\title{
DA UTILIZAÇÃO DOS CONTRATOS DE FACTORING NO BRASIL
}

Thiago Zamineli de Lima

Universidade do Oeste Paulista - UNOESTE, Curso de Direito, Presidente Prudente, SP.

\section{RESUMO}

O presente artigo tem escopo de apresentar o contrato de faturização no Brasil apresentando sua origem na antiguidade, sobretudo na Idade Média com a disseminação pela Europa e Estados Unidos, para, finalmente e, tardiamente chegar ao Brasil em meados de 1982. Inicialmente proibido de utilização por ser incluído como atividade bancária pelo Banco Central do Brasil, o factoring foi permitido posteriormente por não se apresentar como atividade de instituição financeira, nem a ela se assemelhar.

Com cláusulas específicas, a atividade de factoring no fomento mercantil ajuda o pequeno e médio empresário na solução de seus problemas diários. Fomentar, assessorar e promover o desenvolvimento é a finalidade do factoring.

A descaracterização da essência e finalidade do factoring classifica-se em ilícito penal ou contravenção, ressaltando que tal contrato mercantil destina-se exclusivamente a pessoas jurídicas.

Palavras - chave: Faturização. Pessoa Jurídica. Fomento Mercantil.

\section{USE OF FACTORING CONTRACTS IN BRAZIL}

\begin{abstract}
This paper is to present the scope of contract factoring in Brazil presenting its origin in antiquity, especially in the Middle Ages with the spread throughout Europe and the United States to finally and belatedly arriving in Brazil in mid-1982 initially prohibited of use to be included as banking by the Central Bank of Brazil, factoring was subsequently allowed for failing to perform as an activity of a financial institution, nor resemble her.

With specific clauses, the activity of factoring in market promotion helps small and medium businessmen in solving their daily problems. Foster, assist and promote the development is the purpose of factoring.

The characterization of the essence and purpose of factoring is ranked criminal offense or misdemeanor, stressing that such commodity contract solely intended to corporations.
\end{abstract}

Keywords: Factoring. Corporations. Mercantile. 
INTRODUÇÃO

O factoring (fomento mercantil) é contrato pelo qual um empresário (faturizador) presta a outro empresário (faturizado), serviços de administração do crédito concedido e garante o pagamento das faturas emitidas (maturity factoring). É comum, também, o contrato abranger a antecipação do crédito, numa operação de financiamento (conventional factoring).

Em outras palavras, quando uma sociedade empresária concede crédito aos consumidores ou aos adquirentes de seus produtos ou serviços, passa a ter uma preocupação empresarial a mais, ou seja, tem que se preocupar com a administração da concessão do crédito que compreende o controle dos vencimentos, acompanhamento da flutuação das taxas de juros, contatos com os devedores inadimplentes, adoção de medidas assecuratórias do direito creditício etc.

Além disso, o empresário ao conceder crédito, assume o risco de insolvência do devedor. Contudo, a competição econômica, por vezes, não dá outra alternativa ao empresário. Se não criar facilidades de pagamento aos consumidores ou adquirentes, a sociedade empresária pode perdêlos para os concorrentes.

O contrato de fomento mercantil que pode ser referido também como faturização, proposta por Fábio Konder Comparato (1978), tem a função de poupar o empresário das preocupações empresariais decorrentes da outorga de prazos e facilidades para pagamento aos consumidores ou adquirentes.

\section{METODOLOGIA}

A utilização da pesquisa qualitativa demonstra a forma que o pesquisador obteve através de seus estudos bibliográficos, para que, através da legislação específica possa contribuir de maneira dedutiva o desenvolver do presente tema com caráter de esclarecimento.

\section{Evolução histórica}

\subsection{No Mundo}

De origem na antiguidade greco-romana, quando comerciantes incumbiam a agentes, localizada em pontos diversos, a guarda e venda de coisas suas, difundida pela Idade Média, sobretudo na região do Mediterrâneo. O modo de comercializar ganhou um novo folego, na era dos descobrimentos, se operando especialmente no ramo têxtil. Com o passar do tempo, a faturização declinou na Europa, expandindo-se nos Estados Unidos da América. Neste processo, o fomento mercantil sofreu uma evolução: de um mero contrato de comissão para um contrato de 
cessão de crédito, mediante remuneração, onde o antigo comissarista passa a cobrar diretamente do devedor. Esse novo modelo de factoring, que predomina hoje, foi reintroduzido na Europa na década de 1960. É esse mesmo modelo que, tardiamente, veio ao Brasil em 1982.

\subsection{No Brasil}

O factoring surgiu no Brasil no dia 11 de fevereiro de 1982, com a fundação da ANFAC (Associação Nacional de Fomento Comercial), no Rio de Janeiro.

A ANFAC, como entidade precursora, vem atuando ao longo destes anos, na construção de um marco regulatório com base nas experiências hauridas no mercado, destinado a manter a estabilidade institucional e a segurança jurídico-operacional com todas as medidas cabíveis para evitar conflitos de interesses e garantir o nível de profissionalismo da atividade.

O maior desafio das empresas de faturização no Brasil foi a edição da Circular no 703 do Banco Central, de 16 de junho de 1982, que considerou a atividade de fomento mercantil bancária. Desta forma, o factoring tornou-se proibido. De 1982 a 1988, a ANFAC lutou para revogar a medida, e em 1986, o Tribunal Federal de Recursos encerrou o processo em se discutia a legalidade da Circular no 703 do Banco Central, sem resultado.

Apenas em 30 de setembro, com a Circular no 1359, a Circular no 703 foi revogada, permitindo a faturização, enfatizando, porém, que a atividade de factoring não podia ser confundida com atividade de instituição financeira definida na Lei no 4595/64 nem a ela se assimilar.

\section{A natureza bancária do factoring e a legislação brasileira}

O Banco Central já considerou a faturização contrato bancário no início dos anos 1980, mas desde 1989 liberou a atividade de fomento mercantil a qualquer sociedade empresária, independente de prévia autorização. A legislação tributária, por sua vez, conceituou o factoring como sendo "a prestação cumulativa e contínua de serviços de assessoria creditícia, mercadológica, gestão de crédito, seleção de riscos, administração de contas a pagar e a receber, compras de direitos creditórios resultante de vendas mercantis a prazo ou de prestação de serviços" (Lei no 8.981/95 arts. 28 ao 48, revogados pela Lei 9.249/95).

\section{Cláusulas essenciais dos contratos}

Segundo Fran Martins, são cláusulas essenciais dos contratos de factoring:

a) Exclusividade ou totalidade das contas do faturizado: ao faturizado é vedado ceder 
seus créditos à distintas empresas de fomento. Essa exclusividade, portanto, decorre da essência do contrato por envolver não apenas a compra de créditos, mas também assessoria profissional no campo mercadológico, no acompanhamento das contas e na seleção e avaliação dos riscos

b) Duração do contrato: o contrato deve estabelecer prazo, determinado ou indeterminado de duração, período em que o faturizado receberá os serviços da empresa de fomento, pagando os encargos que forem estipulados.

A falta de um período de duração do contrato daria à empresa faturizadora o poder de exercer o odioso controle sobre o exercício da atividade econômica do seu cliente e, por outro lado, a obrigaria a dar continuidade à prestação do serviço que não mais lhe convém. Por esta razão, se o contrato for convencionado por prazo indeterminado, a simples notificação de uma das partes à outra a libera do contrato, liquidando-se as operações já iniciadas.

c) Faculdade de o faturizador escolher as contas: é permitindo ao faturizador selecionar os créditos quando da apresentação das faturas pela empresa emitente dos títulos, oportunidade em que assume os riscos pela operação, não tendo, contra a faturizada, direito de regresso.

Outra razão para facultar-se à empresa de fomento a escolha dos créditos, tão importante quanto o princípio do equilíbrio contratual, diz respeito à segurança da operação. Evita-se a obrigação de a empresa de fomento adquirir a totalidade dos créditos de determinado período e, por consequência, de se tornar refém de operações temerosas ou fraudulentas de seu cliente.

d) Liquidação dos créditos: seu conteúdo dependerá da modalidade contratada. Entre as espécies de factoring, há duas mais utilizadas, denominadas convenctional factoring (também chamado de old line factoring) e maturity factoring (também conhecido como factoring de vencimento): na primeira acontece a antecipação sobre o valor dos títulos contratados no momento da cessão; na segunda não há antecipação, o pagamento ao faturizado se dá no vencimento dos títulos ou posteriormente.

e) Cessão dos créditos: por não se tratar de cessão pura e simples, ao contrato de factoring se aplicam restritivamente regras próprias à transmissão das obrigações previstas nos arts. 286298 do Código Civil.

Em primeiro lugar, há identidade quanto à forma: para ter validade em relação a terceiros, o contrato de fomento deve ser celebrado por instrumento público ou particular (CC, Art. 288)

Em segundo lugar, o devedor deve ser notificado (CC, Art. 289), devendo-se observar que a ausência de notificação não opera ipso facto a perda do direito de cobrança. As defesas do devedor são passíveis de ser opostas na execução ou cobrança fundada em título cambial e, entre elas, pode figurar a de pagamento realizado ao sacador, emitente do título na compra e venda a 
prazo ou na prestação de serviços.

Em terceiro lugar, de forma resumida, fica assentado de que o faturizado responde pela validade e existência do título (exigibilidade), mas não pela solvência do sacado.

Em quarto lugar, o devedor pode opor ao cessionário exceções que tenha contra o cedente (CC, Art. 294).

f) Assunção de riscos pelo faturizador: sua natureza explica a não adoção plena dos princípios cambias quanto ao endosso e responsabilidade do endossante e, igualmente, seu distanciamento do instituto de cessão de crédito no que se refere à cláusula pro solvendo.

g) Remuneração do contrato: sobre os valores adiantados na modalidade conventional podem incidir juros que, entretanto, se submetem, quando não convencionados, ao regramento do Código Civil quanto ao mútuo, não podendo exceder "a taxa que estiver em vigor para a mora no pagamento de impostos devidos à Fazenda Nacional" (CC, Arts. 591 e 406), que corresponde a $1 \%$ ao mês (CTN, Art. 161, § 1으).

Essa taxa pode ser aumentada até o seu dobro por convenção entre as partes, por força de disposição legal (Decreto № 22.626/33 art. 1ำ, Lei da Usura).

De fato, não há tecnicamente mútuo porque o cedente $\mathrm{n}$ ao se obriga a restituir o valor recebido, salvo nos casos em que se constatar a inexistência de crédito ou má-fé do endossante. 0 valor adiantado é o preço dos serviços e da aquisição dos títulos aceitos pela empresa de fomento.

\section{Resultado}

Concluiu-se com a pesquisa que o factoring ou fomento comercial é a prestação continua de serviços, conjugada com aquisição de créditos de empresas, resultante de suas vendas mercantis ou prestação de serviços a prazo. A capitalização e a administração são mecanismos do fomento mercantil, onde a empresa fomentada vende para a factoring seus créditos gerados pelas vendas e serviços e obtém dinheiro vivo, que aumenta seu poder de negociação nas compras a vista de matéria-prima, assim como a factoring pode prestar serviços à empresa fomentada em qualquer área de sua estrutura, deixando o empresário com mais tempo para produzir e vender.

\section{REFERÊNCIAS}

COELHO, ULHOA FABIO. Curso de direito comercial, volume 3 : direito de empresa, 15a Edição. Saraiva, 2013.

NEGRÃO, RICARDO. Manual de Direito Comercial e de Empresas, Títulos de Crédito e Contratos Empresariais, 3a edição. Saraiva, 2011. 
ANFAC - www.anfac.com.br.

http://www.direitobrasil.adv.br/arquivospdf/revista/revistav41/alunos/ve.pdf 